\title{
No Distension of Pharyngoesophageal Segment Opening During Swallowing
}

National Cancer Institute

\section{Source}

National Cancer Institute. No Distension of Pharyngoesophageal Segment Opening

During Swallowing. NCI Thesaurus. Code C127323.

A finding of no distension of pharyngoesophageal segment opening during swallowing with total obstruction of flow. 